\section{Involving dental practitioners in setting the dental research agenda}

\author{
C. Fox, ${ }^{* 1}$ E. J. Kay ${ }^{2}$ and R. Anderson ${ }^{3}$
}

IN BRIEF
- Describes an e-system for capturing
primary dental care practitioners'
unanswered questions relating to practice.
- Evaluates the economic, technical and
operational feasibility of the e-system
to identify practice-relevant research
priorities.
- Describes how The Shirley Glasstone
Hughes Trust involves primary dental
care practitioners in its research
commissioning decision-making.

This paper describes the process set up by the BDA and the Shirley Glasstone Hughes (SGH) Trust as a result of their will to involve dental practitioners in dental research prioritisation, so that funding could be directed towards research that practitioners would find useful. The paper considers the technical, operational and economic feasibility of using an online system to determine the research priorities of primary care practitioners and describes the extent to which the system worked in practice. The aim of the work described was to ensure that the research commissioned by SGH Trust actually served practitioners' needs and promotes the use of evidence in general dental practice.

\section{INTRODUCTION}

In the previous paper in this series we suggested that the identification of research questions that dentists feel are relevant to practice might help to promote dental practices informed by research evidence. We therefore set out to determine a means by which the research questions most relevant to practitioners could be identified and subsequently used to set priorities for the use of the research funds.

Thanks to Shirley Glasstone Hughes, a dentist, researcher and British Dental Association (BDA) member, the Shirley Glasstone Hughes (SGH) Trust Fund was established in 1990. This charitable trust has a remit to provide prizes or scholarships for dental research 'as trustees, in their absolute discretion decide'. Between 1991 and 2005, 41 research projects were funded, valued in total at $£ 678,000 .^{1}$ In 2005, the trustees commissioned an evaluation of the output from the fund. This assessed the relevance and usefulness to dental practitioners of the research that had been funded by the trust over the previous 15 years. This was to determine whether the

'Researcher, Collaboration for the Advancement of Medical Education Research and Assessment (CAMERA), Plymouth University Peninsula Schools of Medicine and Dentistry; ${ }^{2}$ Foundation Dean and Professor of Dental Public Health, Public Health Academic Consultant, Plymouth University Peninsula Schools of Medicine and Dentistry; ${ }^{3}$ Associate Professor of Health Economics and Evaluation, Peninsula Technology Assessment Group, University of Exeter Medical School, University of Exeter ${ }^{*}$ Correspondence to: C. Fox

Email: chris.fox@plymouth.ac.uk

\section{Refereed Paper}

Accepted 19 June 2014

DOI: $10.1038 /$ sj.bdj.2014.807

${ }^{\circledR}$ British Dental Journal 2014; 217: 307-310

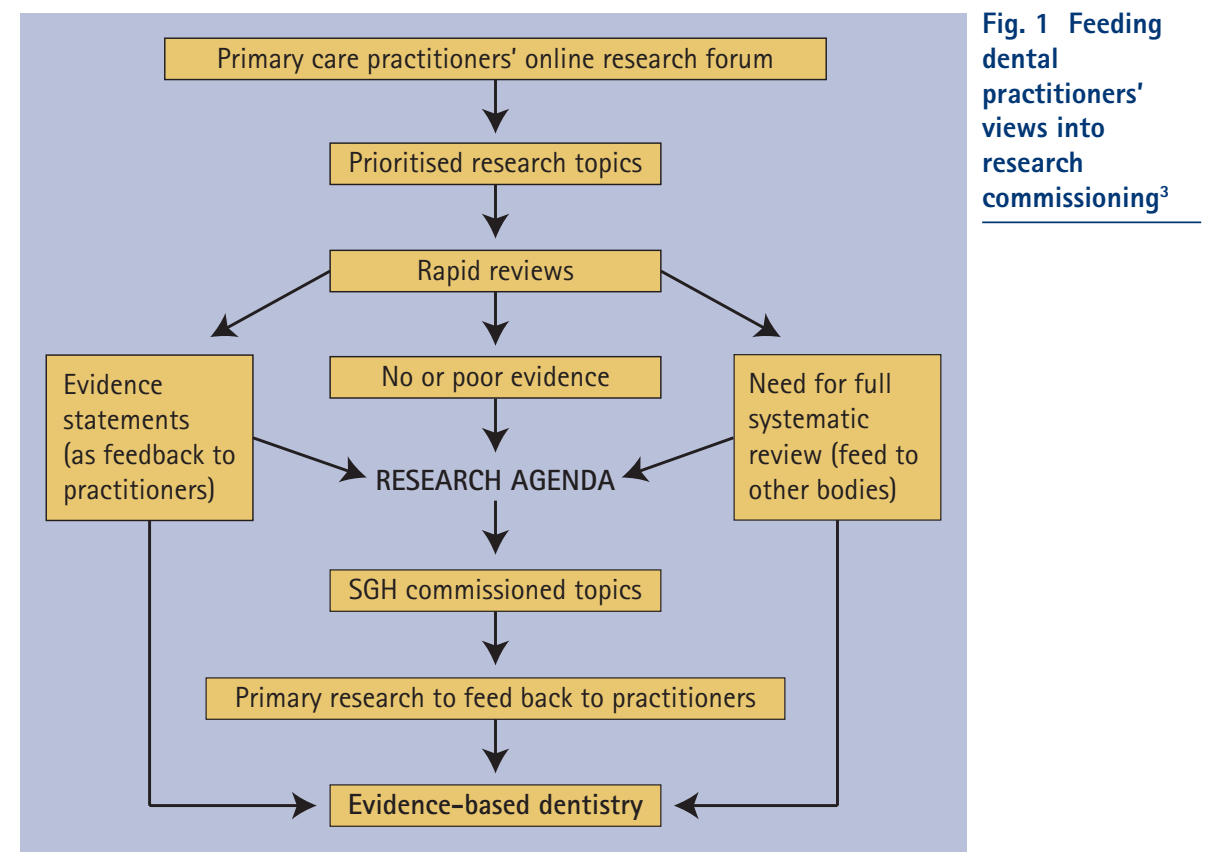

relevance of the research funded by the SGH could be improved. ${ }^{2}$

Two key recommendations (of a total of seven) arose from this evaluation:

1. The SGH Fund should continue to fund research led by and involving nonacademic dentists, that is, primary care practitioners

2. Greater effort should be made to ensure SGH funded work addresses themes of direct relevance to primary dental care.

Therefore in order to enact these recommendations it was necessary to explore mechanisms that would inform the trust about the day-to-day evidence needs of primary care practitioners. To this end a web-portal was established that gave practitioners the opportunity to nominate subjects that they felt were worthy of research funding. Thus a research agenda-setting process for general practitioners was created and the intention was to attract as many UK dental practitioners as possible to voice their opinion on what they need to know from research. The ultimate aim was to ensure that any research funded by the trust would be research that practitioners wanted, and found useful and usable.

\section{A PROCESS TO INFORM RESEARCH AGENDA-SETTING BY DENTAL PRACTITIONERS}

The initial process for generating practitioners' unaddressed questions, and for 
prioritising and processing the relevant available evidence, is illustrated in Figure $1 .{ }^{3}$

Figure 1 shows that, for prioritised topics identified through the online topic nomination and voting system, a literature search followed by a 'rapid review' of the available research evidence was undertaken. The results of these rapid reviews were disseminated to practitioners and research commissioners through user-friendly research summaries. 'Rapid review' draws upon the structured processes of a systematic review, but is delivered with clearly identifiable constraint and short time frame. Rapid reviews undertaken in a period of one calendar month aim to determine and provide a narrative synthesis of the nature of the evidence available regarding the identified topic. This was fed back to practitioners (through the web portal and other media).

If research evidence available was insufficient or inconclusive to be of benefit to dental practitioners, the subject was fed to other funding bodies (NIHR, Cochrane, etc.) in an attempt to stimulate further systematic reviews or research funding in order to strengthen the evidence. However, if a topic considered a priority by practitioners was found to have no, or very poor research evidence to underpin practice and it was considered relevant to decision-making in practice, the topic was highlighted to SGH Trustees for potential SGH research funding. Overall, the idea was that once research on the practitioner-identified topic had been funded and carried out, the research findings would be disseminated to practitioners (via the web-portal and other media) and this would facilitate evidence-based practice. Thus, 'research waste' ${ }^{4}$ would be avoided.

Table 1 describes the process in detail and Figure 2 shows how the topics appeared on the website. ${ }^{3}$

Each time a new potential research topic was introduced on to the website by a practitioner, participants had an opportunity to vote. Practitioners could indicate whether they felt the topic to be important and relevant to them by giving a positive vote or, if they felt the subject to be unimportant or irrelevant to their day to day dentistry, they could give a negative vote. Thus the level of priority it was seen as having by the practitioners using the website was determined. Each month the most highly prioritised topic that is, the one with the most positive votes (after deducting the number of negative votes) went forward for rapid review of the evidence currently available relating to that topic.

\section{EVALUATION OF THE RESEARCH PRIORITISATION SYSTEM}

Assessment of the feasibility and effectiveness of new processes enabled the success of the

\section{Table 1 Description of components of the research agenda-setting process}

\begin{tabular}{|c|c|}
\hline Process component & Description \\
\hline Research forum & $\begin{array}{l}\text { A web-based system (WBS) to provide dentists with a repository for } \\
\text { their day-to-day most needed practice-related research topics/ques- } \\
\text { tions to be nominated for primary research. An open format, with no } \\
\text { structure of the question required, no background explanation to the } \\
\text { topic, and no details of topic originator required. }\end{array}$ \\
\hline \multirow{4}{*}{ Prioritised research topics } & $\begin{array}{l}\text { The most recurrent nominated research topic/question by primary } \\
\text { dental care practitioners (PDCPs) in any given period. }\end{array}$ \\
\hline & $\begin{array}{l}\text { Phase } 1 \text { (of WBS): all nominated topics reviewed by SGHTF Chair and } \\
\text { administrator for most recurrent topic. Also capacity to formulate a } \\
\text { searchable question based upon PICO principle. }\end{array}$ \\
\hline & $\begin{array}{l}\text { (PICO A systematic means to convert topics/issues into searchable/ } \\
\text { answerable questions, by defining the: [P] population, [I] intervention, } \\
\text { [C] comparison, [0] outcome.) }\end{array}$ \\
\hline & $\begin{array}{l}\text { Phase 2: a voting system built into the WBS to enable registrant PDCPS } \\
\text { to vote (promote/demote) nominated topics. Most voted-for nominated } \\
\text { topic in any voting period became the subject of a rapid evidence review. }\end{array}$ \\
\hline Rapid reviews & $\begin{array}{l}\text { A comparatively fast process for undertaking a search for, and } \\
\text { critical appraisal of, the best available evidence relating to a prioritised } \\
\text { topic/question. }\end{array}$ \\
\hline Evidence statements & $\begin{array}{l}\text { A short, jargon-free, summary of the critically-appraised evidence } \\
\text { relating to the prioritised topic, for information to PDCPs. Available } \\
\text { online and in journal. }\end{array}$ \\
\hline No/poor evidence & $\begin{array}{l}\text { The outcome of the rapid review indicates a lack, or lack of quality } \\
\text { evidence on the prioritised topic. Leads to being considered in the } \\
\text { SGHTF research agenda. }\end{array}$ \\
\hline Need for full systematic review & $\begin{array}{l}\text { The outcome of the rapid review indicates the availability of a significant } \\
\text { quantity of evidence that is beyond the scope of a rapid review. This } \\
\text { warrants a full systematic review by another body in order that conclu- } \\
\text { sions about the level of evidence on the prioritised topic can be drawn. }\end{array}$ \\
\hline Research agenda & $\begin{array}{l}\text { A list of prioritised, rapidly-reviewed topics where little or no } \\
\text { evidence has been found and which are suited to SGHTF primary } \\
\text { research commissioning. }\end{array}$ \\
\hline SGH commissioned topics & The SGHTF board commissions primary research on the selected topic. \\
\hline $\begin{array}{l}\text { Primary research to feed } \\
\text { back to practitioners }\end{array}$ & $\begin{array}{l}\text { The output of the primary research is disseminated to PCDPs through } \\
\text { a range of media. }\end{array}$ \\
\hline Evidence-based dentistry & $\begin{array}{l}\text { Such evidence arises both from the evidence statements produced and } \\
\text { the outputs arising from the commissioned primary research, thereby } \\
\text { supporting evidence-based dentistry }\end{array}$ \\
\hline
\end{tabular}

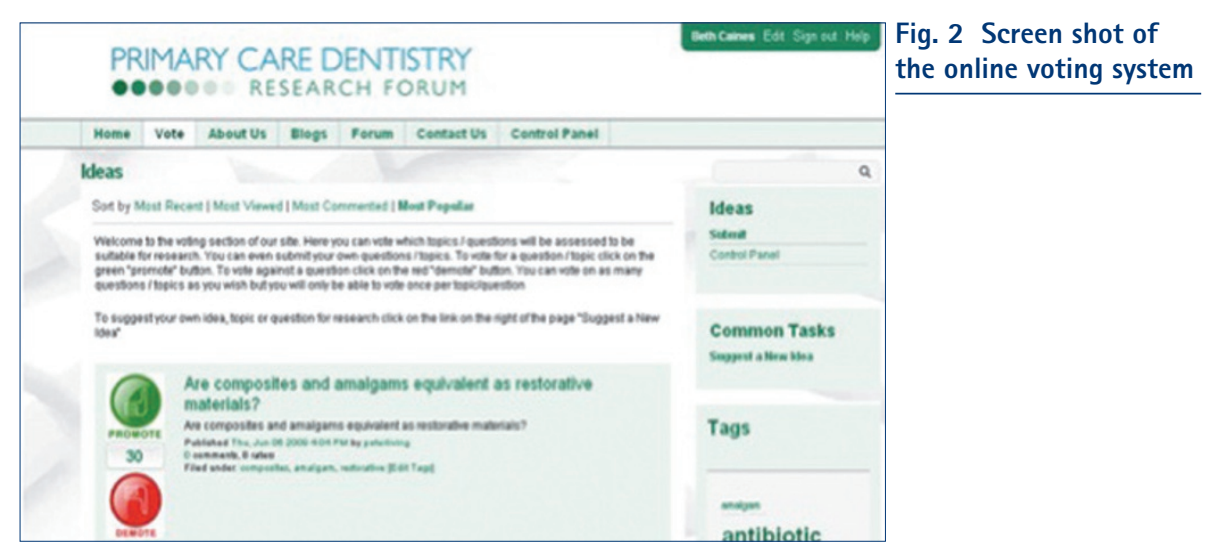

initiative to be evaluated, in order to develop understanding about whether, how and why the system/process worked and in what way. Figure 3 illustrates this interactive evaluation ${ }^{3-8}$ and Table 2 highlights aspects of feasibility of the research agenda-setting process., ${ }^{3,5}$

Evaluating the effectiveness of the system for promoting evidence-based practice in dentistry included consideration of the extent to which the website and prioritisation system encouraged or supported practitioners to utilise evidence to underpin their professional decisions. In order to do so it was necessary to assess the level of effectiveness of each of the key components of the system. Therefore we needed to evaluate how effective the system was at generating topic nominations from practitioners; how well the voting system worked in achieving nominated topic prioritisation; the extent to which the 


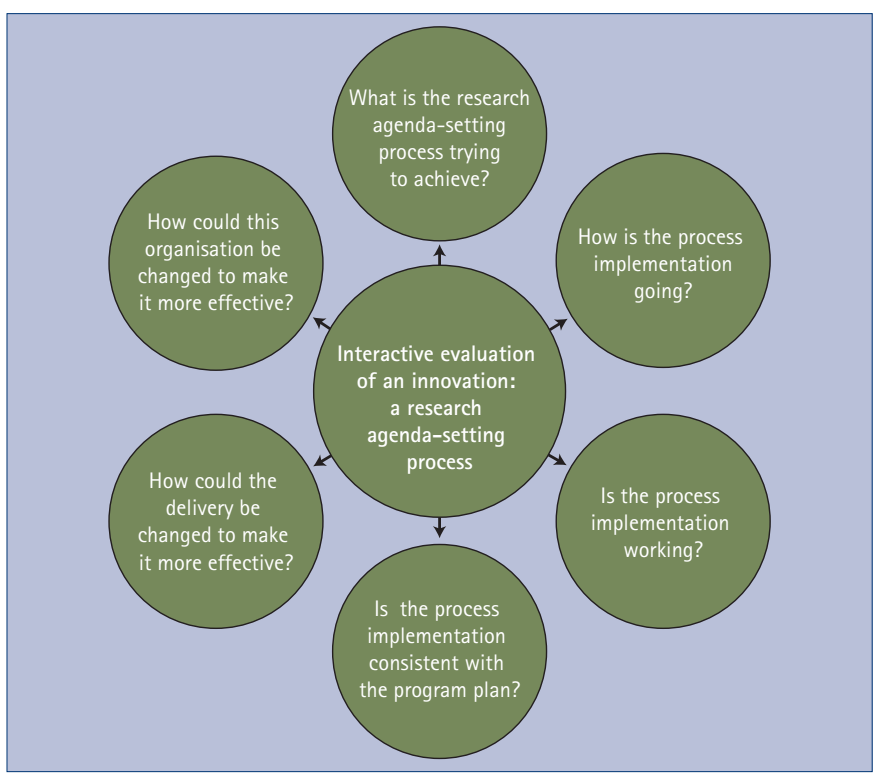

Table 2 Aspects of feasibility of the research agenda-setting process ${ }^{3,5}$

Feasibility measure
How does the forum attract participants/a meaningful level of participants?
How does the forum capture the topics, or uncertainties, of PDCPs, and in what form?
How does the online voting system attract participants?
How does the opportunity to demote as well as promote topics influence the
prioritisation process?
What is the impact of the 3 month rule for topics' availability for votes?
What is the nature of the topics prioritised by PDCPs?
How does the new rapid review process work in practice?
What value is there in producing evidence statements?
What is a suitable format for evidence statements?
Who and how are evidence statements intended to benefit?
What is involved in the setting up of a research forum?
What is involved in the running of a research forum?
What does 'rapid' mean in this process? A 20 day cycle? Is it sustainable?
What is the role of the reviewer in the production of rapid reviews?
What are the implications for a process that is 'resource-constrained' and cyclical?
What difference will these evidence statements make to evidence-based dentistry?
How?

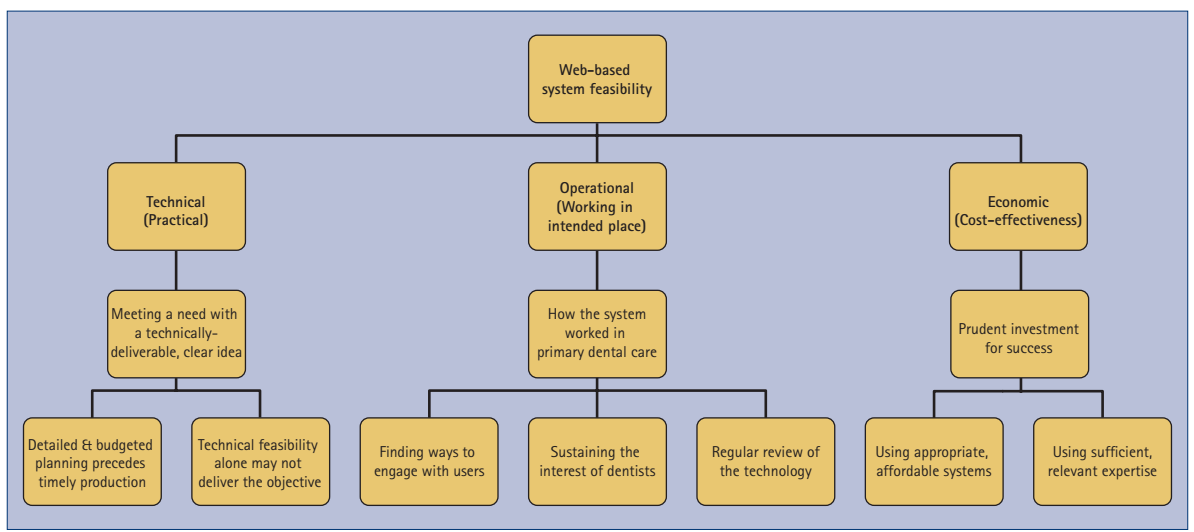

Fig. 4 Perceived influences upon web-based system feasibility ${ }^{3,5}$

rapid reviews were read and remembered and finally, whether dentists and research commissioners valued the evidence statements.

The evaluation consisted of a mixed methods approach, using several forms of data

Fig. 3 Interactive evaluation $^{6-8}$

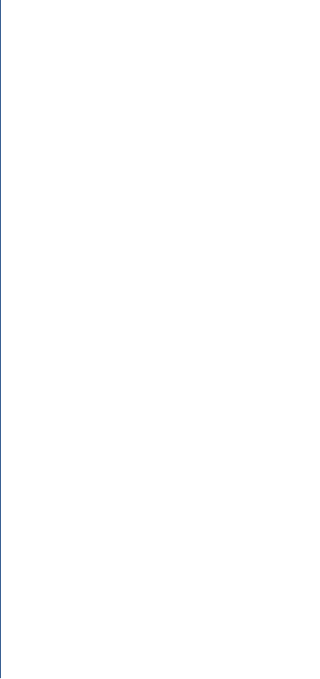


(59\%) agreed that the topics reviewed had been relevant to their day to day practice. Evidence summaries therefore appear to be recognised as a valuable aspect of the SGH web initiative and thus continue to be produced.

Finally, the online survey of the SGH research commissioners showed that all felt the system had helped 'a great deal' in providing a basis for making decisions about which research should be commissioned or funded. All commissioners felt that the initiative had given them a representative and much better picture of the research needs of practising dentists. They did, however, recognise that the web based system needed to grow its user level and that if this could be achieved, the success of the initiative would be greatly enhanced.

\section{CONCLUSION}

The new and ambitious initiative set up by the SGH Trust was introduced in an effort to involve and place primary dental practitioners at the heart of research agenda- setting. The evaluation has shown that it is feasible to set up and run a web-based system to generate practice-relevant research topics and themes and that this can be achieved with relatively modest resources and within short timescales. However, due to underuse of the system its effectiveness in achieving its purpose was limited.

The evaluation has clearly shown that it is feasible to design and implement a process to generate rapid reviews of the topics practitioners say are of interest to them. In addition, for those who accessed the evidence summaries, they appear to have been effective in as much as they were perceived as useful and informed decision making. However, the low level of participation in the website meant that dentists' awareness of the summaries was low. It is hoped that the redesigned 'Curious about' website (see below) and the addition of verifiable CPD will improve this.

In conclusion, the new process that was designed and implemented to generate userfriendly evidence summaries was feasible. However, the dissemination of information that dentists had said they wanted and needed was of limited effectiveness because of the low level of use by primary dental practitioners. The evaluation presented the information we needed in order to provide a usable, useful and economically viable means of involving dental practitioners in setting the research agenda and utilising research results in practice. It is hoped that practitioners' involvement will continue to grow.

\section{SGH/BDA INITIATIVE: THE 'CURIOUS ABOUT' WEBSITE}

The latest version of the Curious about website offers verifiable CPD to practitioners accessing the rapid reviews. In addition to dentists being able to submit topics, and in an effort to maximise topic nomination and therefore support a practitioner-driven research agenda, BDA committee members (dentists acting on behalf of dentists), officers and staff can also submit topics to the SGH commissioners. BDA staff, especially the advice teams, are in continuous contact with members and are aware of the issues that practitioners have and the questions they would like answered. During the time the site has been live the nature of the suggestions has varied widely, and interest seems to be being maintained.

The BDA Curious about page, which is described in this paper, can be accessed at http://www.bda.org/dentists/education/sgh/ about_sgh.aspx

The contribution of Dr Ellena O'Selmo, Shirley Glasstone Hughes Foundation of the British Dental Association, to the early drafting of this paper based upon the research and writing of the primary author (undertaken with guidance from the other authors) is gratefully acknowledged.

1. The Shirley Glasstone Hughes Trust Fund. The SGHTF - shaping the future of primary dental care research. The Shirley Glasstone Hughes Trust Fund, Unpublished, 2008.

2. Miguel J C, Kay E J, Lowe J C. Shirley Glasstone Hughes Memorial Prize for Dental Research: an evaluation of the output 15 years after the Trust's inception. Br Dent J 2007; 203: 535-541.

3. Fox C. Evaluation of a process for research agendasetting in primary dental care. PhD thesis, Peninsula College of Medicine and Dentistry, 2012.

4. Chalmers I, Glasziou P. Avoidable waste in the production and reporting of research evidence. Lancet 2009: 374: 86-89.

5. Norman R, Corbitt G. The operational feasibility perspective. Journal of Systems Management 1991; 42: $10-15$.

6. Murariu C. How to measure the effectiveness of web designs. Six Revisions, 2011. Online article available at http://sixrevisions.com/web_design/how-tomeasure-the-effectiveness-of-web-designs/ (Accessed July 2014).

7. Pope C. Mays N (eds). Qualitative research in health care. Oxford: Blackwell Publishing Ltd, 2006.

8. Dunlop M. Reflections on Mira: interactive evaluation in information retrieval. J Am Soc Inform Sci 2000; 51: 1269-1274.

9. O'Cathain J, Murphy E, Nicholl J. Research methods and reporting. Three techniques for integrating data in mixed methods studies. BMJ 2010; 341: 1147-1150. 